\section{Traumatic Oculomotor Nerve Palsy}

Dong Bee Kook, Byung Ho Park, Euna Hwang, Chung Hun Kim

Department of Plastic and Reconstructive Surgery, CHA Bundang Medical Center, CHA University, Seongnam, Korea

Correspondence: Chung Hun Kim

Department of Plastic and Reconstructive Surgery, CHA Bundang Medical Center, CHA University, 59 Yatap-ro, Bundang-gu, Seongnam 463-712, Korea Tel: +82-31-780-5280, Fax: +82-31-780-5285, E-mail: chkimps@cha.ac.kr

This article was presented at the 70th Congress of the Korean Society of Plastic and Reconstructive Surgeons on November 9-11, 2012 in Seoul, Korea.

No potential conflict of interest relevant to this article was reported.

Received: 26 Nov $2013 \bullet$ Revised: 17 Sep 2014 • Accepted: 18 Sep 2014 pISSN: 2234-6163・ elSSN: 2234-6171

http://dx.doi.org/10.5999/aps.2015.42.2.250 • Arch Plast Surg 2015;42:250-252

Copyright (C) 2015 The Korean Society of Plastic and Reconstructive Surgeons This is an Open Access article distributed under the terms of the Creative Commons Attribution Non-Commercial License (http://creativecommons.org/licenses/by-nc/3.0n) medium, provided the original work is properly cited.

Oculomotor nerve palsy generally presents with mydriasis, blepharoptosis, and impairment of extraocular muscle movement. The incidence of primary traumatic oculomotor nerve palsy in craniocerebral trauma is approximately $1.2 \%[1]$. The causes of oculomotor nerve palsy are congenital, traumatic, vascular, migrainous, and parainfectious. Especially in children, it is often caused by congenital factors, postnatal trauma, or infections [2]. Previous reports indicated that complete recovery is unusual [3]. Here, we report a case of a child with traumatic oculomotor nerve palsy accompanying an orbitozygomaticomaxillary fracture. To our knowledge, it is the first such case report to appear in

Fig. 1.

One week post-trauma. Complete ptosis and a dilated pupil were noted. a Korean plastic surgery journal and is of note because the patient experienced a near-complete recovery, contrary to the grave prognoses described in previous case reports. An 8-year-old girl was admitted to the hospital after a car accident. The patient had no specific past history. Right periorbital swelling was too severe for the patient to be able to open her right eye, and therefore the pupil size discrepancy was only recognized after four days. The right pupil was dilated up to $5.5 \mathrm{~mm}$, compared with $2.0 \mathrm{~mm}$ dilation on the unaffected side. The complete impairment of eye adduction was also noted in the affected eye. However, results of the forced duction test were normal. Thus, her right eyeball was deviated to the inferolateral side in the neutral gaze (right exotropia) (Fig. 1). Complete blepharoptosis remained in the right upper eyelid after the periorbital swelling subsided seven days after the trauma. These findings were consistent with oculomotor nerve palsy. Visual acuity was normal at 20/20. The laboratory data, other aspects of the medical history, and the review of systems were in the normal range. There were also no specific neurological abnormalities except oculomotor nerve palsy. A facial computed tomography scan displayed a right orbitozygomaticomaxillary fracture and a nasal bone fracture, which were so minimal that they were not expected to affect oculomotor nerve function. Magnetic resonance images also revealed no abnormal findings associated with oculomotor nerve palsy. A cerebrospinal fluid test was not performed because there was no leakage of cerebrospinal fluid. One week after the trauma, an operation was performed to address the facial bone fracture. We employed steroid therapy to reduce periorbital swelling and possible endoneurial edema, in order to prevent secondary neuronal damage. Solu-Medrol (1 $\mathrm{mg} / \mathrm{kg}$, methylprednisolone) was injected

\section{Table 1. Flowsheet of ocular examination}

\begin{tabular}{|c|c|c|c|}
\hline $\begin{array}{l}\text { Post- } \\
\text { traumatic } \\
\text { period }\end{array}$ & $\begin{array}{c}\text { Pupil } \\
\text { diameter } \\
(\mathrm{mm}, 0 \mathrm{O} / \mathrm{OS})\end{array}$ & $\begin{array}{c}\text { Diplopia } \\
\text { (direction) }\end{array}$ & $\begin{array}{c}\text { Height of } \\
\text { palpebral } \\
\text { fissure }(\mathrm{mm})\end{array}$ \\
\hline 1 wk & $5.5 / 2$ & $\begin{array}{l}\text { Supraduction, } \\
\text { infraduction }\end{array}$ & 0 \\
\hline $2 w k$ & $5.5 / 2$ & No change & 1 \\
\hline 4 wk & $4 / 2$ & No change & 3 \\
\hline 8 wk & $4 / 2$ & No change & 5 \\
\hline 20 wk & $5 / 2.5$ & No change & 6.5 \\
\hline $1 \mathrm{yr}$ & $4 / 3$ & Improved & 9 \\
\hline
\end{tabular}



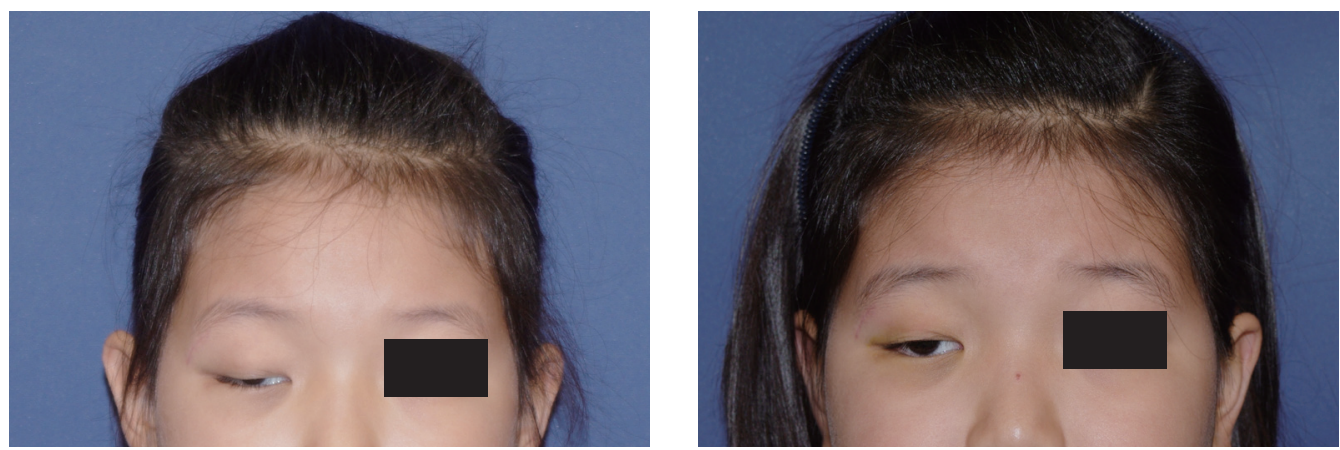

Fig. 3.

Eight weeks post-trauma.

Levator function was improved compared to at 4 weeks.

Fig. 2.

Four weeks post-trauma. The movement of paretic extraocular muscles and the amount of ptosis were somewhat improved. Levator function was measured as no more than $3 \mathrm{~mm}$.

intravenously for four days after the operation. After postoperative day five, prednisolone was administered and tapered gradually for six days. During the first three weeks, there was little improvement of levator function and the pupillary reflex (Fig. 1). However, at four weeks post-trauma, the movement of the paretic extraocular muscles and the state of ptosis were slightly improved. Levator function was measured at $3 \mathrm{~mm}$ (Table 1, Fig. 2). After 20 weeks, levator function was gradually improved and a measurement of $6.5 \mathrm{~mm}$ elevation was taken. However, pupillary function had not recovered to its normal range (Figs. $3,4)$. One year after the trauma, levator function and pupillary function had almost recovered to the normal range (Fig. 5). The patient is still being followed and is expected to improve further. In adults, common causes of oculomotor nerve palsy are aneurysms, trauma, diabetes mellitus, and neoplasms. The relevant neoplasms are mostly pituitary adenomas and metastatic tumors [4]. The prognosis of oculomotor nerve palsy varies according to its etiology and associated cranial nerve problems. In children, common causes are congenital factors, trauma, inflammation, neoplasms, aneurysms, and others [4]. The exact pathophysiology of oculomotor palsy is not well understood. However, it is generally assumed that lesions in the sphenocavernous region, the orbital apex, and the brain stem may affect the oculomotor nerve. Direct injury or indirect compression can also result in palsy. If the cause is inflammation, postinfectious neuropathy may affect the nerve, but this mechanism of pathogenesis is not well understood [4]. Clinically, pupillary function shows great variability. Pupil-sparing oculomotor palsy can be caused by the infarction of the

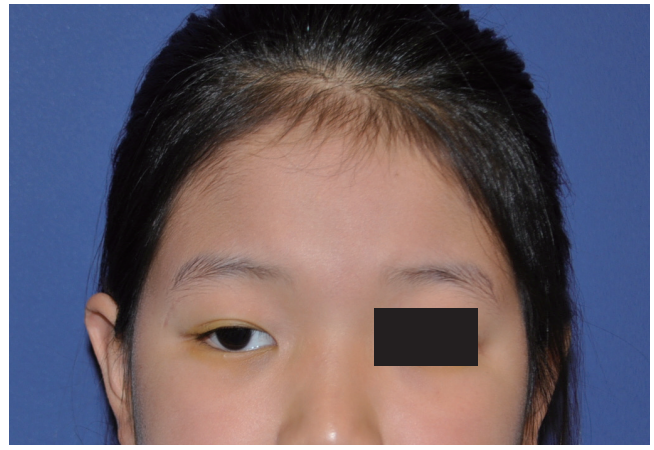

Fig. 4.

Twenty weeks post-trauma. Levator function was gradually improved, as shown by a measurement of $6.5 \mathrm{~mm}$ elevation. However, pupillary function had not recovered to the normal range. oculomotor nerve. Such patients may have diabetes mellitus [5]. Oculomotor nerve palsy that presents with smaller pupils may be due to Horner's syndrome or diabetic autonomic neuropathy. Partial oculomotor nerve palsy can resolve in one to three months [4]. The improvement of visual acuity has been known to be difficult to achieve [2]. Many patients may develop amblyopia. In fact, in pediatric cases of oculomotor nerve palsy, it is difficult to measure visual acuity quantitatively because young children are incompliant. However, regardless of the practical difficulties involved in measuring the visual acuity of children, visual acuity is known to be impaired in this condition. In our case, we saw a considerable improvement of levator function during the first 20 weeks. During the first eight weeks, about $50 \%$ of levator function was recovered. However, medial rectus muscle function had not recovered at that point. It was necessary to wait at least six months for the recovery of function in the pupil and medial rectus muscle because only a small restoration of the pupil size was noted after five months. One year after the trauma, levator and pupillary function almost recovered to the normal range (Fig. 5). Based on the course of the patient's recovery, we surmise that these functions will continue to improve with time. The patient is still being followed. Fortunately, the patient's visual acuity is normal. In our case, treatment 
Fig. 5.

One year post-trauma. Levator and papillary function had almost recovered to the normal range.

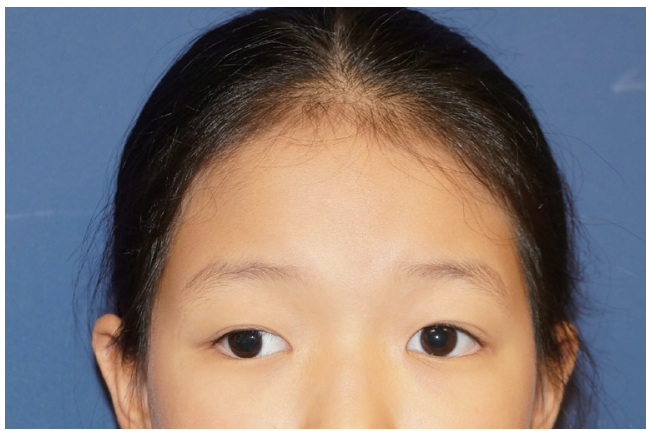

was limited to early steroid therapy and occlusion therapy. The prognosis of oculomotor nerve palsy varies according to its etiology and the associated neurological problems. Some authors suggest waiting for at least six months before strabismus surgery, which permits the cause of oculomotor palsy to be evaluated and allows for possible spontaneous recovery [2]. A surgical approach, including strabismus surgery and ptosis surgery, should be considered according to the degree of recovery. We suggest that plastic surgeons keep in mind that facial trauma may occur in combination with various cranial nerve injuries and therefore should evaluate patients with facial trauma for the symptoms and signs of cranial nerve injuries.

\section{References}

1. Kaido T, Tanaka Y, Kanemoto Y, et al. Traumatic oculomotor nerve palsy. J Clin Neurosci 2006;13:852-5.

2. Schumacher-Feero LA, Yoo KW, Solari FM, et al.

Third cranial nerve palsy in children. Am J Ophthalmol $1999 ; 128: 216-21$.

3. Elston JS. Traumatic third nerve palsy. Br J Ophthalmol 1984;68:538-43.

4. Saeki N, Yotsukura J, Adachi E, et al. Isolated superior division oculomotor palsy in a child with spontaneous recovery. J Clin Neurosci 2000;7:62-4.

5. Sato H, Hashimoto T, Yoneda S, et al. Lymphoma as a cause of isolated oculomotor nerve palsy. J Clin Neurosci 2011 ; $18: 1256-8$
Delayed Methicillin-Resistant Staphylococcus aureus Infection on a Mandibular Angle Fracture with Absorbable Plates

Han Moi Choi, Soon Heum Kim, Cheol Keun Kim, Hyun Gon Choi, Dong Hyeok Shin, Ki Il Uhm, Dongin Jo

Department of Plastic Surgery, Konkuk University Hospital, Konkuk University School of Medicine, Chungju, Korea

Correspondence: Dongin Jo

Department of Plastic Surgery, Konkuk University Hospital, Konkuk University School of Medicine, 82 Gugwon-daero, Chungju 380-704, Korea

Tel: +82-10-8742-0831, Fax: +82-43-840-8962, E-mail: dijo@medigate.net

No potential conflict of interest relevant to this article was reported

Received: 13 May 2014 • Revised: 12 Jul 2014 • Accepted: 12 Jul 2014 plSSN: 2234-6163 • elSSN: 2234-6171

http://dx.doi.org/10.5999/aps.2015.42.2.252 • Arch Plast Surg 2015;42:252-254

Copyright (C) 2015 The Korean Society of Plastic and Reconstructive Surgeons This is an Open Access article distributed under the terms of the Creative Commons Attribution Non-Commercial License (http://creativecommons.org/licenses/by-nc/3.0/) which permits unrestricted non-commerciluse, distribution, and reproduction in medium, provided the original work is properly cited.

Absorbable fixation is used worldwide for bone fixation. Because it is absorbed into the body by a hydrolysis process, removal is unnecessary. Inflammation, swelling, and acute infection can occur [1], but with less frequency in delayed type infections [2]. The authors report on a case of infection that was delayed for one year in a patient who underwent mandibular fracture fixation using absorbable plates. A 17-year-old male arrived as an outpatient with a chief complaint of a left mandibular mass. His past history included seizure and mental retardation due to hydrocephalus (diagnosed at six months after birth) and a medication history of asthma. One year ago, he underwent a procedure of open reduction using absorbable plates on his mandible. Five weeks after fixation, wound dehiscence and purulent discharge was noted and revision was performed. Methicillin-resistant Staphylococcus aureus (MRSA) was cultured from discharge of the wound.

Vancomycin $500 \mathrm{mg}$ was administered in IV form for seven days until no microbium was cultured from the wound. After revision, the wound showed improvement.

When the patient visited our outpatient department, a firm round mass was palpated at the left mandibular margin (Fig. 1). The nature of the mass was hard and fixed with adjacent tissues. Redness, heating sense, 